of this transition to the coupling constant is rather large. For example, in ethane, the three transition states which give the large contributions to the $\mathrm{H}_{1}-\mathrm{H}_{2}$ coupling constant are almost the same. In the ${ }^{13} \mathrm{C}-\mathrm{H}$ coupling constant, the transitions which give the largest and second largest contributions are almost those to the lowest vacant orbitals or so and their energy values vary, being $-19--27 \mathrm{eV}$ and $-13--32 \mathrm{eV}$, respectively. The ratios of the largest and second largest contributions to the coupling constant vary, being $1-5$. For example in ethane, the two transition states which give the largest and second largest contributions to the ${ }^{13} \mathrm{C}-\mathrm{H}$ coupling constant and their energy values are almost the same, but in methanol the two values are rather different. Accordingly, application of the mean excitation energy approximation seems to be meaningless. In conclusion, the contribution of excitation state to the two NMR parameters is not limited to that of the highest occupied and lowest vacant orbitals, but spreads to rather a large scale.

Acknowledgement The authors thank Dr. A. Tajiri, Chemical Research Institute of Non-Aqueous Solutions and Dr. A. Ohmichi, Department of Chemistry, Tohoku University, for providing a computerprogram which could be used with the M-CNDO/2 method. They also thank Dr. H. Ogata, Faculty of Engineering, Tokyo University, for kindly providing charts of photoelectron spectra and for helpful suggestions. They are also grateful to the staff of Kyoto University Computer Center where the calculations were carried out.

\title{
A Novel Synthesis of Isopavine Ring System
}

\author{
Tetsuji Kametani and Kunio Ogasawara \\ Pharmaceutical Institute, Tohoku University 1 )
}

(Received July 26, 1972)

In 1958, Battersby and Yeowell ${ }^{2)}$ have reported the synthesis of the isopavine (II) from the benzylaminoacetal (I) preceding the discovery of natural isopavine alkaloids. ${ }^{3,4)}$<smiles>COc1ccc(CC(NC(OC)OC)c2ccc(OC)c(OC)c2)cc1OC</smiles>

I<smiles></smiles>

II

Chart 1

1) Location: Aobayama, Sendai.

2) A.R. Battersby and D.A. Yeowell, J. Chem. Soc., 1958, 1988.

3) T. Kametani, "The Chemistry of the Isoquinoline Alkaloids," Hirokawa (Tokyo) and Elsevier (Amsterdam), 1968, p. 235.

4) S.M. Kupchan and A. Yoshitake, J. Org. Chem., 34, 1062 (1969). 
We have now developed a new type of isopavine synthesis which will be described here. Total syntheses of several isopavine alkaloids have been described, ${ }^{4-7)}$ but the routes employed are all based on Battersby's method. In 1968, Pfeifer and his co-workers found that treatment of hydrastinine (III) and cotarnine (IV) with diazomethane afforded the ring-expanded products (V) and (VI), respectively. ${ }^{8)}$ Recently, Bernhard and Snieckus ${ }^{9}$ reinvestigated this reaction on hydrastinine perchlorate (III) and they proved the aziridinium salt (VII) to be an actual intermediate, which was then transformed into $\mathrm{V}$ under the solvolytic conditions.<smiles>[R1]c1c2cc(c3c1OCO3)[N+](=[R])C([R])C2</smiles><smiles>CCCCCC</smiles>

III : $\mathrm{R}_{1}=\mathrm{R}_{2}=\mathrm{H}, \mathrm{R}_{3}=\mathrm{Me}$

IV $: \mathrm{R}_{1}=\mathrm{OMe}, \mathrm{R}_{2}=\mathrm{H}, \mathrm{R}_{3}=\mathrm{Me}$

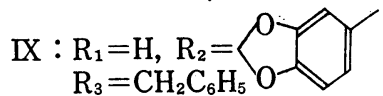<smiles>[R]C1CN([R2])C([R2])Cc2cc3c(c(OC)c21)OCO3</smiles>

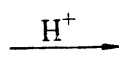

$\mathrm{V}: \mathrm{R}_{1}=\mathrm{R}_{2}=\mathrm{H}, \mathrm{R}_{3}=\mathrm{Me}$

$\mathrm{VI}: \mathrm{R}_{1}=\mathrm{OMe}, \mathrm{R}_{2}=\mathrm{H}, \mathrm{R}_{3}=\mathrm{Me}$

$\mathrm{XII}: \begin{aligned} \mathrm{R}_{1} & =\mathrm{H}, \mathrm{R}_{2}=\langle \\ \mathrm{R}_{3} & =\mathrm{CH}_{2} \mathrm{C}_{6} \mathrm{H}_{5}\end{aligned}$

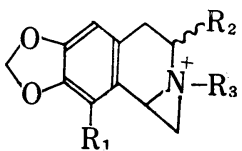

\section{$\mathrm{MeOH}$}

VIII : $\mathrm{R}_{1}=\mathrm{OMe}, \mathrm{R}_{2} \doteq \mathrm{H}, \mathrm{R}_{3}=\mathrm{Me}$
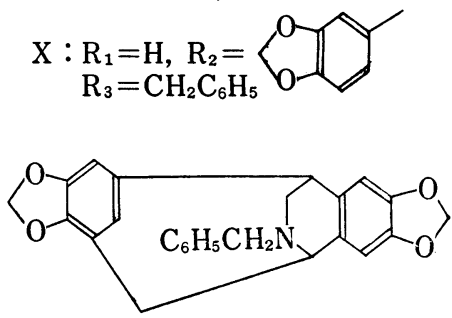

XI

Chart 2

We have been interested in effecting a similar reaction sequence with a 3 -substituted isoquinolinium salt (IX) producing an aziridinium salt (X), which would then be transformed into an isopavine (XI) via a one-step ring expansion-ring closure process. Thus, the iodide (IX) ${ }^{11)}$ prepared from piperoin via a five-steps operation, was treated with an excess of ethereal diazomethane at $0^{\circ}$ in methylene chloride. An amorphous compound, possibly the crude one $(\mathrm{X})$, resulted from evaporation of the solvent, was treated with methanolic hydrochloric acid to give the desired isopavine (XI), $\mathrm{mp} 86-88^{\circ}$, in $4.2 \%$ yield and the ring-expanded 3 -benzazepine (XII), $\mathrm{mp} 141-142^{\circ}$, in $28.0 \%$ yield, after the filtration of the reaction mixture through a silica gel column. The mass spectral feature of the compound (XI) was entirely in accord with the characteristic of isopavines. ${ }^{12,13)}$ The above amorphous compound on heating in $3 \%$ methanolic hydrogen chloride gave the 3-benzazepine (XII) in $49.0 \%$ yield. The compound (XII) gave rise to the isopavine (XI) in $69.9 \%$ yield on treating with ethanolic hydrochloric acid $(1: 1)$ at room temperature for five days. ${ }^{5,6}$

Acknowledgement We thank Miss A. Kawakami and Miss T. Yoshida for microanalyses, Miss A. Ujiie for the NMR spectral measurement, and Mr. T. Ohuchi for the mass spectral measurement.

5) S.F. Dyke and A.C. Ellis, Tetrahedron, 27, 3803 (1971).

6) D.W. Brown, S.F. Dyke, G. Hardy, and M. Sainsbury, Tetrahedron Letters, 1969, 1515.

7) M. Sainsbury, D.W. Brown, S.F. Dyke, and G. Hardy, Tetrahedron, 25, 1881 (1969).

8) B. Goeber, S. Pfeifer, V. Hanus, and G. Engelhardt, Arch. Pharm., 301, 763 (1968).

9) H.O. Bernhard and V. Snieckus, Tetrahedron, 27, 2091 (1971).

10) Cf. D.R. Crist and N.J. Leonard, Angew. Chem. Internat. Edn., 8, 962 (1969).

11) Microanalyses and spectral data (IR, NMR, and mass spectra) were consistent with the suggested structure for all the new compounds.

12) L. Dolejs and V. Hanus, Coll. Czech. Chem. Commun., 33, 600 (1968).

13) L. Dolejs and J. Slavik, Coll. Czech, Chem. Commun., 33, 3971 (1968). 